\title{
Torque Ripple Reduction in Direct Torque Control of Five-Phase Induction Motor Using Fuzzy Controller with Optimized Voltage Vector Selection Strategy
}

\author{
Hye Ung Shin*, Seong Yun Kang** and Kyo-Beum Lee ${ }^{\dagger}$
}

\begin{abstract}
This paper presents a torque ripple reduction method of direct torque control (DTC) using fuzzy controller with optimal selection strategy of voltage vectors in a five-phase induction motor. The conventional DTC method has some drawbacks. First, switching frequency changes according to the hysteresis bands and motor's speed. Second, the torque ripple is rapidly increased in long control period. In order to solve these problems, some/most papers have proposed torque ripple reduction methods by using the optimal duty ratio of the non-zero voltage vector. However, these methods are complicated in accordance with the parameter. If this drawback is eliminated, the torque ripple can be reduced compared with conventional method. In addition, the DTC can be simply controlled without the use of the parameter. Therefore, the proposed algorithm is changing the voltage vector insertion time by using the designed fuzzy controller. Also, the optimized voltage vector selection method is used in accordance with the torque error. Simulation and experimental results show effectiveness of the proposed control algorithm.
\end{abstract}

Keywords: Torque ripple reduction, Five-phase induction motor drive, Direct torque control, Fuzzy controller

\section{Introduction}

Multiphase motor control has more advantages than the three phase-motor drive system. If the number of phases increases, the motor drive system possesses multiple voltage vectors. Also, multiphase motor helps reducing the rotor harmonic currents, lowering the dc link current harmonics, reducing the current per phase without increasing the voltage per phase, and having many voltage vectors by increasing the number of phases [1]. Above all, by increasing the number of voltage vectors, it is possible to select an optimal voltage vector for the high performance of the direct torque control (DTC) in five-phase induction motor $[2,3]$.

In the conventional DTC scheme, both the torque and the stator flux errors between the reference and the estimated value are directly compared, and the appropriate voltage vector is produced by a switching table $[4,5]$. By optimal selection of the inverter switch states in each sampling period, the DTC achieves rapid and effective control of the stator flux and torque [6]. However, the advantage of the rapid response includes the increased torque ripple. The torque ripple causes increased noise and unstable operation of the motor. Therefore, the torque

$\dagger \quad$ Corresponding Author: Dept. of Electrical and Electronic Engineering, Ajou University, Korea. (kyl@ajou.ac.kr)

* Dept. of Electrical and Electronic Engineering, Ajou University,

Korea. (hyeung123@naver.com)

** Dawonsys Co., Ltd., Ansan, Korea. (ksy00510@naver.com)

Received: August 17, 2016; Accepted: March 12, 2017 ripple reduction method becomes essential to solve these problems.

Recently, many papers are dealing with the torque ripple reduction methods [7-11]. A torque ripple reduction method that aims to make the instantaneous torque equal with the reference value at the end of the cycle is researched. Another method is that the average torque equals to the reference value among the entire cycle. In addition, there is a method that aims to the torque ripple RMS value over one cycle to be minimal. In these methods, insertion time of the voltage vector $\left(T_{s}\right)$ is calculated for the torque ripple reduction. The equation for calculating $T_{s}$ is required for a number of motor parameters. Therefore, the motor parameters are significantly affected by the torque ripple reduction. In order to solve this problem, [12] proposed that the formula of $T_{s}$ is fixed as a constant value. However, this method has some drawbacks. First, when $T_{s}$ has a low value, the dynamic performance is decreased. Second, $T_{s}$ is found by tuning. The fixed $T_{s}$ value needs to be changed by considering the torque error to solve this problem. The fuzzy controller is applied in the proposed torque ripple reduction algorithm for changing $T_{s}$ [13]. The input of the fuzzy controller is the torque error, and its output is the $T_{s}$ [14].

This paper presents DTC controlled technique for fivephase induction machine. Relation between the switching states and voltage vectors in five-phase induction motor drive is analyzed, and this paper proposes an improved torque ripple reduction method using the fuzzy control 


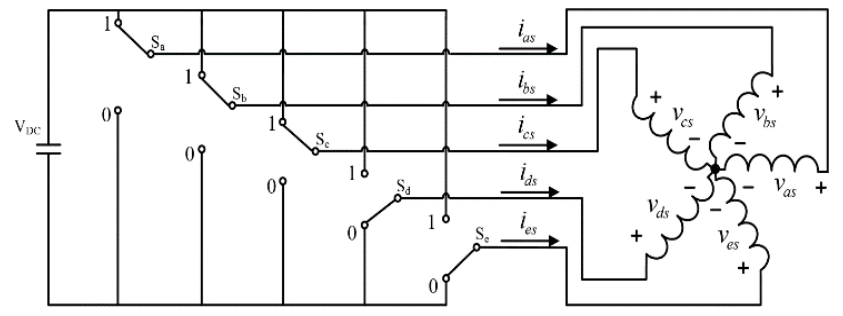

Fig. 1. Circuit of a five-phase induction motor

which is applied to find the optimal $T_{s}$ under change of the motor speed and the torque error. In addition, this paper suggests a method of considering torque error and motor speed to select an optimal voltage vector. The proposed method is verified by simulation and experimental results.

\section{Voltage Vector in Five-phase Inverter}

The schematic of star winding and VSI in five-phase induction motor is shown in Fig. 1. Two-level inverter is used in this paper to drive five-phase induction motor. A five-phase induction motor uses a full pitch concentrated winding, instead of the traditional sinusoidal winding distribution. This winding structure is designed with a rectangular distribution to better accommodate the quasirectangular input currents provided by the five-phase. The five-phase inverter contains two switches in each leg. The switches of each leg operate in a complementary manner. $\left[\begin{array}{lllll}\mathrm{S}_{\mathrm{a}} & \mathrm{S}_{\mathrm{b}} & \mathrm{S}_{\mathrm{c}} & \mathrm{S}_{\mathrm{d}} & \mathrm{S}_{\mathrm{e}}\end{array}\right]$ shows the five-phase inverter switching states. The components of each switching state have 0 (off state of the upper switch) or 1 (on state of the upper switch) [15]. Therefore, five-phase inverter has 32 switching states.

The non-zero voltage vectors of thirty and zero-voltage vectors of [000000], [111111] are compounded in these switching states. 32 voltage vectors are included in three class vectors each, have different magnitudes of the voltage vectors. Additionally, 10 sectors with different voltage vectors phases are components of those three set vectors. The formula for the phase and the voltage magnitude values of the voltage vectors is determined by switching states, which is expressed as:

$$
\begin{gathered}
f_{d 1 q 1 s}^{s}=\frac{2}{5}\left(f_{a s}+a f_{b s}+a^{2} f_{c s}+a^{3} f_{d s}+a^{4} f_{e s}\right) \\
=f_{d s 1}^{s}+j f_{q s 1}^{s} \\
\theta_{p h}=\tan ^{-1}\left(\frac{f_{q s 1}^{s}}{f_{d s 1}^{s}}\right) \\
V_{s}=\frac{2}{5} V_{D C}\left(S_{a}+a S_{b}+a^{2} S_{c}+a^{3} S_{d}+a^{4} S_{e}\right)
\end{gathered}
$$

where, $f^{s}{ }_{d I q l s}$ shows the d-q axis stationary frame complex space vector, $f_{a b c d e s}$ shows the complex space vector of each phase, $S_{a b c d e}$ indicates the five-phase inverter switching

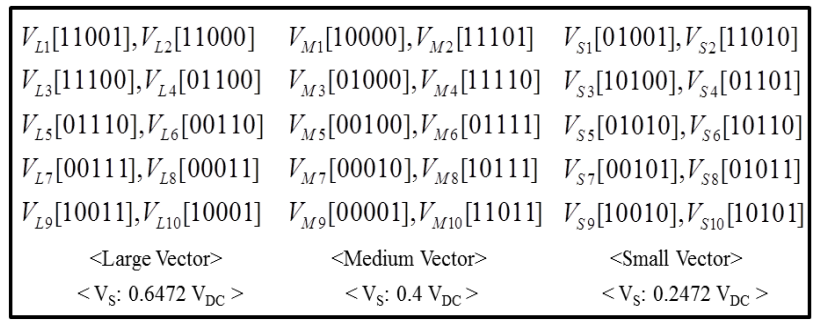

Fig. 2. Voltage vectors of each switching state in five-phase inverter

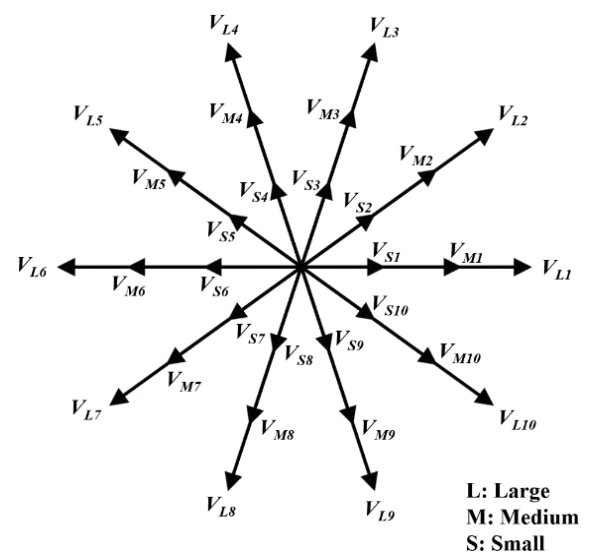

Fig. 3. Plane of voltage vectors for five-phase inverter

function, $\theta_{p h}$ represents the phase angle, $a=e^{j 2 \pi / 5}$, and $V_{s}$ reflects the voltage magnitude. (3) used as a formula for the voltage magnitude calculation determined by each voltage vector state [1]. The magnitude of voltage vectors of the five-phase inverter switching states using the formula (3) is shown in Fig. 2. The calculated voltage magnitude has three classes of the voltage value $(0.6472$ $V_{D C}, 0.4 V_{D C}$, and $\left.0.2472 V_{D C}\right)$. (1) and (2) are used for the phase calculation of voltage vector.

Each calculated phase of the voltage vectors has one of the values which are divided by intervals of $36^{\circ}$. The fivephase inverter's voltage vectors plane is shown in Fig. 3. The voltage magnitude and the phase are represented by the voltage vector plane [16]. The increased number of voltage vectors of five-phase inverter compared to its three-phase counterparts helps increasing the choices of the optimum voltage vector selection [15]. As a result, this helps to reduce the torque ripple and conduct high performance drive in the DTC.

\section{Proposed Torque Ripple Reduction Method in Five-phase Induction Motor}

\subsection{Direct torque control}

Without considering the complex field-orientation block and inner current regulation loop, the DTC provides a very quick and precise torque response. This allows the DTC to 
be a simple, fast response, and effective control method. The voltage vector selection in switching table of the DTC allows the torque and the flux to be directly controlled. Additionally, for the optimal selecting of the voltage vector, the rotor flux position is demanded. The voltage model for estimating the rotor flux position is used in this paper. (4) and (5) are equations of the voltage model for the rotor flux position:

$$
\begin{aligned}
& v_{d q s}^{s}=R_{s} i_{d q s}^{s}+\frac{d \lambda_{d q s}^{s}}{d t} \Rightarrow \lambda_{d q s}^{s}=\int\left(v_{d q s}^{s}-R_{s} i_{d q s}^{s}\right) d t \\
& \lambda_{d q r}^{s}=\frac{L_{r}}{L_{m}}\left(\lambda_{d q s}^{s}-\sigma L_{s} i_{d q s}^{s}\right) \Rightarrow \theta_{e}=\tan ^{-1}\left(\frac{\lambda_{q r}^{s}}{\lambda_{d r}^{s}}\right)
\end{aligned}
$$

where, $v_{d q s}^{s}, R_{s}, i_{d q s}^{s}, \lambda_{d q s}^{s}, \lambda_{d q r}^{s}, \sigma, L_{s}, L r, L_{m}$, and $\theta_{e}$ indicate the $\mathrm{d}-\mathrm{q}$ axis voltage of the synchronous reference frame, stator resistance, stator $\mathrm{d}-\mathrm{q}$ axis current, flux of stator stationary reference frame, flux of rotor stationary reference frame, leakage flux, stator inductance, rotor inductance, mutual inductance, and flux angle. Without requirement of the motor speed in the flux estimation, the voltage model is a convenient flux estimator for sensorless induction motor drives. Moreover, a few motor parameters are needed for the voltage model to estimate the rotor flux position. Therefore, the voltage model is often used in DTC [17].

The estimated rotor flux position is divided by ten sectors listed in the Table 1. Thus, the rotor flux position is included in the sector number. Table 2 shows the voltage vector selection lookup table, with the torque comparator containing four-levels. The $O_{T}$ is the torque comparator output and $O_{F}$ is the result of the flux comparator. The

Table 1. Angle value about sector number

\begin{tabular}{c|c}
\hline Number of sector & Angle \\
\hline 1 & $0^{\circ}<\theta_{e} \leq 36^{\circ}$ \\
\hline 2 & $36^{\circ}<\theta_{e} \leq 72^{\circ}$ \\
\hline 3 & $72^{\circ}<\theta_{e} \leq 108^{\circ}$ \\
\hline 4 & $108^{\circ}<\theta_{e} \leq 144^{\circ}$ \\
\hline 5 & $144^{\circ}<\theta_{e} \leq 180^{\circ}$ \\
\hline 6 & $180^{\circ}<\theta_{e} \leq 216^{\circ}$ \\
\hline 7 & $216^{\circ}<\theta_{e} \leq 252^{\circ}$ \\
\hline 8 & $252^{\circ}<\theta_{e} \leq 288^{\circ}$ \\
\hline 9 & $288^{\circ}<\theta_{e} \leq 314^{\circ}$ \\
\hline 10 & $314^{\circ}<\theta_{e} \leq 360^{\circ}$ \\
\hline
\end{tabular}

\begin{tabular}{|c|c|c|c|c|c|c|c|c|c|c|c|}
\hline \multirow{2}{*}{$\mathrm{O}_{\mathrm{F}}$} & \multirow{2}{*}{$\mathrm{O}_{\mathrm{T}}$} & \multicolumn{10}{|c|}{ Number of sector } \\
\hline & & 1 & 2 & 3 & 4 & 5 & 6 & 7 & 8 & 9 & 10 \\
\hline \multirow{4}{*}{-1} & +3 & $\mathrm{~V}_{\mathrm{L} 4}$ & $\mathrm{~V}_{\mathrm{L} 5}$ & $\mathrm{~V}_{\mathrm{L} 6}$ & $V_{\mathrm{L} 7}$ & $\mathrm{~V}_{\mathrm{L} 8}$ & $\mathrm{~V}_{\mathrm{L} 9}$ & $\mathrm{~V}_{\mathrm{L} 10}$ & $\mathrm{~V}_{\mathrm{L} 1}$ & $V_{L 2}$ & $\mathrm{~V}_{\mathrm{L} 3}$ \\
\hline & +2 & $\mathrm{~V}_{\mathrm{M} 4}$ & $\mathrm{~V}_{\mathrm{M} 5}$ & $\mathrm{~V}_{\mathrm{M} 6}$ & $V_{M 7}$ & $V_{M 8}$ & $\mathrm{~V}_{\mathrm{M} 9}$ & $\mathrm{~V}_{\mathrm{M} 10}$ & $\mathrm{~V}_{\mathrm{M} 1}$ & $V_{\mathrm{M} 2}$ & $\mathrm{~V}_{\mathrm{M} 3}$ \\
\hline & +1 & $\mathrm{~V}_{\mathrm{S} 4}$ & $\mathrm{~V}_{\mathrm{S} 5}$ & $\mathrm{~V}_{\mathrm{S} 6}$ & $\mathrm{~V}_{\mathrm{S} 7}$ & $\mathrm{~V}_{\mathrm{S} 8}$ & $\mathrm{~V}_{\mathrm{S} 9}$ & $\mathrm{~V}_{\mathrm{S} 10}$ & $\mathrm{~V}_{\mathrm{S} 1}$ & $\mathrm{~V}_{\mathrm{S} 2}$ & $\mathrm{~V}_{\mathrm{S} 3}$ \\
\hline & 0 & $\mathrm{~V}_{31}$ & $\mathrm{~V}_{0}$ & $\mathrm{~V}_{31}$ & $\mathrm{~V}_{0}$ & $\mathrm{~V}_{31}$ & $\mathrm{~V}_{0}$ & $\mathrm{~V}_{31}$ & $\mathrm{~V}_{0}$ & $\mathrm{~V}_{31}$ & $\mathrm{~V}_{0}$ \\
\hline \multirow{4}{*}{+1} & +3 & $\mathrm{~V}_{\mathrm{L} 3}$ & $\mathrm{~V}_{\mathrm{L} 4}$ & $V_{L 5}$ & $\mathrm{~V}_{\mathrm{L} 6}$ & $\mathrm{~V}_{\mathrm{L} 7}$ & $\mathrm{~V}_{\mathrm{L} 8}$ & $\mathrm{~V}_{\mathrm{L} 9}$ & $\mathrm{~V}_{\mathrm{L} 10}$ & $\mathrm{~V}_{\mathrm{L} 1}$ & $\mathrm{~V}_{\mathrm{L} 2}$ \\
\hline & +2 & $V_{\mathrm{M} 3}$ & $\mathrm{~V}_{\mathrm{M} 4}$ & $\mathrm{~V}_{\mathrm{M} 5}$ & $\mathrm{~V}_{\mathrm{M} 6}$ & $V_{M 7}$ & $\mathrm{~V}_{\mathrm{M} 8}$ & $\mathrm{~V}_{\mathrm{M} 9}$ & $V_{\mathrm{M} 10}$ & $\mathrm{~V}_{\mathrm{M} 1}$ & $V_{\mathrm{M} 2}$ \\
\hline & +1 & $\mathrm{~V}_{\mathrm{S} 3}$ & $V_{S 4}$ & $\mathrm{~V}_{\mathrm{S} 5}$ & $\mathrm{~V}_{\mathrm{S} 6}$ & $\mathrm{~V}_{\mathrm{S} 7}$ & $\mathrm{~V}_{\mathrm{S} 8}$ & $\mathrm{~V}_{\mathrm{S} 9}$ & $\mathrm{~V}_{\mathrm{S} 10}$ & $\mathrm{~V}_{\mathrm{S} 1}$ & $\mathrm{~V}_{\mathrm{S} 2}$ \\
\hline & 0 & $\mathrm{~V}_{0}$ & $V_{31}$ & $\mathrm{~V}_{0}$ & $\mathrm{~V}_{31}$ & $\mathrm{~V}_{0}$ & $\mathrm{~V}_{31}$ & $\mathrm{~V}_{0}$ & $\mathrm{~V}_{31}$ & $\mathrm{~V}_{0}$ & $\mathrm{~V}_{31}$ \\
\hline
\end{tabular}

Table 2. Voltage vector selection lookup table number of the section along with the torque and the flux comparators outputs make up the lookup table [18]. When $O_{F}$ value becomes 1 , the flux increases. In contrast, when $O_{F}$ value is set to -1 , it means that the flux decreases. Otherwise, the torque increases followed by the change of the $O_{T}(+3,+2,+1)$.

For example, when the value of the $O_{T}$ is +3 , the torque increases when selecting the large voltage vector. The fastest response time and largest torque value are driven from the large voltage vector. The torque is increased by the medium voltage vector when the value of the $O_{T}$ is +2 . The small voltage vector is selected to increase the torque value when that of $O_{T}$ is +1 . In addition, if the value of the $O_{T}$ is 0 , the torque becomes decreased by the zero voltage vector.

\subsection{Proposed method}

The conventional torque ripple reduction method in the DTC of the three-phase induction motor is shown in Fig. 4 [12]. By considering the real torque and the torque reference, the optimal time is calculated at the end of the current period by this method. The slopes of the rising torque and the falling torque are necessary to calculate the optimal time.

The slopes of the rising torque and the falling torque are determined by using (6) and (7) [19]:

$$
\begin{aligned}
S_{1}= & -\frac{T_{e}}{\left(\frac{R_{s}}{\sigma L_{s}}+\frac{R_{r}}{\sigma L_{r}}\right)^{-1}}+\frac{3 P}{4} \frac{L_{m}}{\sigma L_{s} L_{r}}\left\{-V_{d s}^{*} \lambda_{q r}+V_{q s}^{*} \lambda_{d r}\right. \\
& \left.-\omega_{m} \cdot\left(\lambda_{d s} \lambda_{q s}+\lambda_{d r} \lambda_{q r}\right)\right\} \\
S_{0}= & -\frac{T_{e}}{\left(\frac{R_{s}}{\sigma L_{s}}+\frac{R_{r}}{\sigma L_{r}}\right)^{-1}}-\frac{3 P}{4} \frac{L_{m}}{\sigma L_{s} L_{r}} \cdot \omega_{m}\left(\lambda_{d s} \lambda_{q s}+\lambda_{d r} \lambda_{q r}\right)
\end{aligned}
$$

where $S_{l}, S_{0}, v_{d q s}, \lambda_{d q s}, \lambda_{d q r}, \omega_{m}, P$, and $T_{e}$ are the slope of the torque by nonzero voltage vector, the slope of the

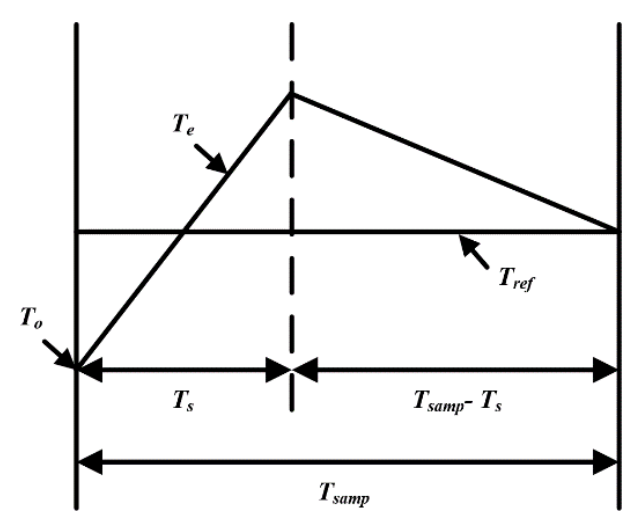

Fig. 4. Conventional torque ripple reduction method in three-phase induction motor 
torque by zero voltage vector, $d-q$ axis stator voltage, $d-q$ axis stator flux, $d-q$ axis rotor flux, motor angular velocity, number of poles, and the electromagnetic torque. The effective vector insertion time can be expressed as:

$$
T_{s}=\frac{T_{r e f}-T_{o}-S_{0} T_{\text {samp }}}{\left(S_{1}-S_{0}\right) T_{\text {samp }}}=\frac{T_{r e f}-T_{o}}{\left(S_{1}-S_{0}\right) T_{\text {samp }}}+\frac{-S_{0}}{S_{1}-S_{0}}
$$

where $T_{s}$ is the effective vector insertion time, $T_{\text {ref }}$ is the torque reference, $T_{0}$ is the initial torque, and $T_{\text {samp }}$ is the control period. According to the speed these parameters are changed. Therefore, those values are not determined. If (6) and (7) are used for calculating the effective time for the vector injection, as (6) and (7) are composed of many motor parameters, the effective vector insertion time does not have an optimal value. (8) can be redefined as follows to solve this problem:

$$
\begin{aligned}
T_{s}=\left|\frac{E_{T}}{K_{T}}\right|+\left|\frac{E_{F}}{K_{F}}\right| & =\left|\frac{T_{r e f}-T_{o}}{K_{T}}\right|+\left|\frac{\lambda_{r e f}-\lambda_{0}}{K_{F}}\right| \\
E_{T} & =T_{r e f}-T_{o} \\
E_{F} & =\lambda_{r e f}-\lambda_{0}
\end{aligned}
$$

where $K_{T}$ and $K_{F}$ are constant values. By changing the values as (9), (9) is independent of the motor parameters. However, this conventional method has two drawbacks. First, the characteristic of this conventional method is that the torque response time and the ripple are determined by $K_{T}$ and $K_{F}$. When the $K_{T}$ and the $K_{F}$ have small values, $T_{s}$ is decreased. As a result, the flux and torque ripple are reduced and the response speed decreases, however when the $K_{T}$ and the $K_{F}$ have greater value, the injection time of the non-zero vector increases. As a result, the response time is improved.

Otherwise, the flux and the torque ripple are increased. Second, the conventional method cannot use the effective voltage vector during the whole control period. Because the denominator of the conventional method equation has a fixed value. For example, if the control condition needs the high speed and torque, the speed and torque are not controlled by the reference when using the conventional method. Because the conventional method does not have a high effective voltage vector injection time ratio in the control period.

In order to solve the drawbacks, this paper proposes a method of changing the $K_{T}$ by using a fuzzy controller with considering the motor speed. $K_{F}$ is rated flux value. Because, the effect of the $K_{F}$ is much smaller. In addition, voltage vector injection time formula of conventional method is (9) which simplifies (8). (9) is used in the proposed method. However, the difference between the conventional method and the proposed method is complement the conventional drawback by changing the value of $K_{T}$ without using a fixed constant by using the fuzzy controller.

(12) and (13) are inputs of the fuzzy controller:

$$
\begin{gathered}
e T_{e}(k)=T_{r e f}(k)-T_{c a l}(k) \\
c e T_{e}(k)=e T_{e}(k)-e T_{e}(k-1)
\end{gathered}
$$

where $e T_{e}$ is the torque error and $c e T_{e}$ is the torque error variation. The information of the torque error is included in the input values that are used in the fuzzy controller. Therefore, $T_{\mathrm{s}}$ is optimal time for the torque ripple reduction.

Fig. 5 presents the proposed fuzzy system block diagram. Inputs of fuzzy controller are all normalized in the interval of $[-1,1]$. The maximum value is scaled to 1 by inserting the input to fuzzy controller. After that, by using the membership function, the output in fuzzification area is calculated.

The membership function of the fuzzy controller is shown in Fig. 6. The torque error allows the membership function to be controlled. Through the simulation and testing, the graphs of membership functions are refined. The linguistic labels used to describe the fuzzy sets were 'Negative Big' (NB), 'Negative Medium' (NM), 'Negative Small' (NS), 'Zero' (Z), 'Positive Small' (PS), 'Positive Medium' (PM), 'Positive Big' (PB) [13]. It is possible to assign the set of decision rules as shown in Table 3 . The fuzzy rules are extracted from the simulation and the experiment results about the process. Each control input has seven fuzzy sets so that there are at most 49 fuzzy rules [20-23].

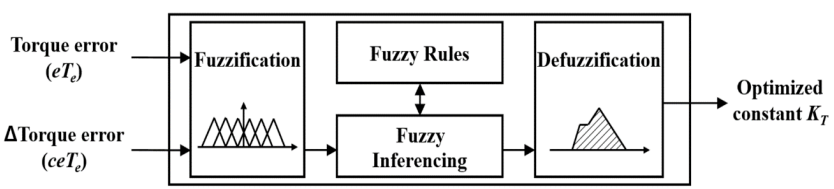

Fig. 5. Fuzzy system block diagram
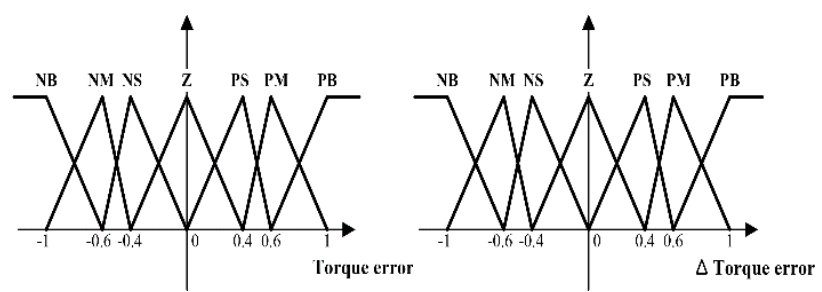

Fig. 6. Membership function of proposed fuzzy system

Table 3. Rule base of proposed fuzzy system

\begin{tabular}{c|c|c|c|c|c|c|c}
\hline$c e T_{e}$ & NB & NM & NS & Z & PS & PM & PB \\
\hline NB & PB & PB & NM & NM & PS & PS & Z \\
\hline NM & PB & NM & NM & PS & PS & Z & NS \\
\hline NS & NM & NM & PS & PS & Z & NS & NS \\
\hline Z & NM & PS & PS & Z & NS & NS & PM \\
\hline PS & PS & PS & Z & NS & NS & PM & PM \\
\hline PM & PS & Z & NS & NS & PM & PM & PS \\
\hline PB & Z & NS & NS & PM & PM & PS & PS \\
\hline
\end{tabular}




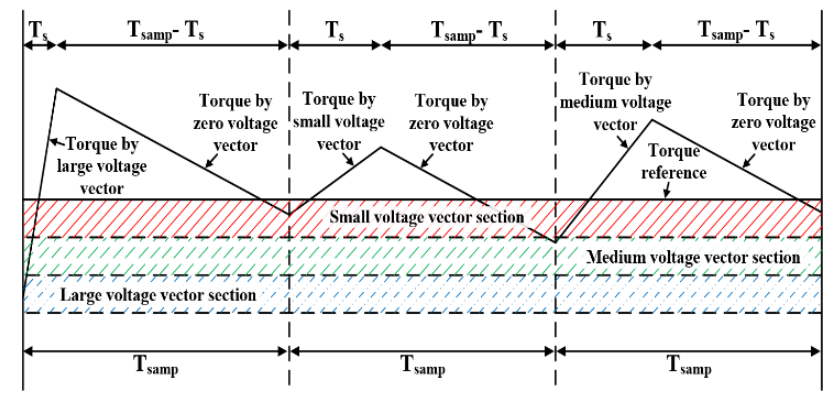

Fig. 7. Proposed method for torque ripple reduction in fivephase induction motor

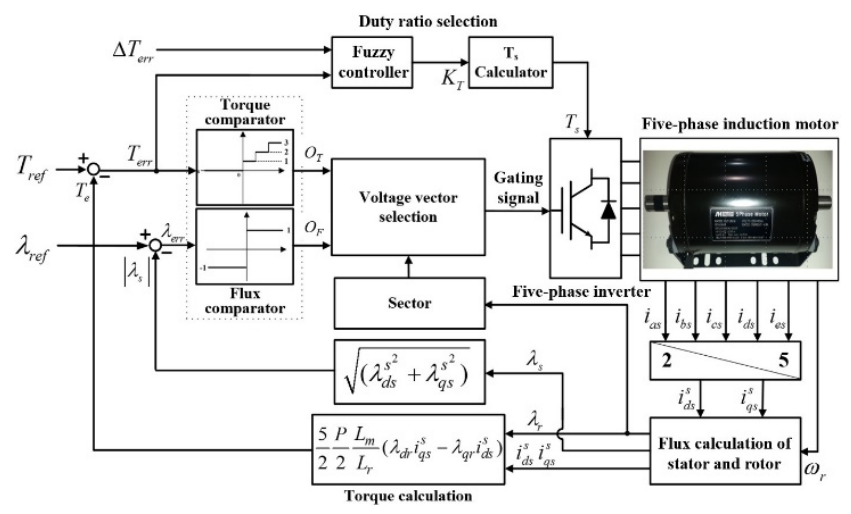

Fig. 8. Block diagram of proposed all system

The optimal value of the $K_{T}$ is decided by defuzzificating of the fuzzy controller. As a result, the proposed method overcomes the weakness of the conventional method by using the designed fuzzy system. The proposed torque ripple reduction method in the five-phase induction motor is shown in Fig. 7. The five-phase inverter can choose among three voltage vectors of different sizes. The voltage vector section according to the position of the torque and the speed of the motor helps to select the voltage vectors. For instance, the torque is rapidly increased when the large voltage vector is selected such as the first section of Fig. 7. On the other hand, the torque is smoothly increased when the small voltage vector is selected such as the second section of Fig. 7. Therefore, by applying this method, the proposed method can reduce torque ripple. Additionally, only zero voltage vector is used for the torque ripple decrease. Thus the reduced slope of the torque equals to three sections. The control block of the proposed method is shown in Fig. 9. The algorithm for the torque ripple reduction method is based on the control block diagram shown in Fig. 8.

\section{Simulation and Experiment Results}

\subsection{Simulation results}

Simulations have been performed using the PLECS tool to verify the performance of the proposed method. The

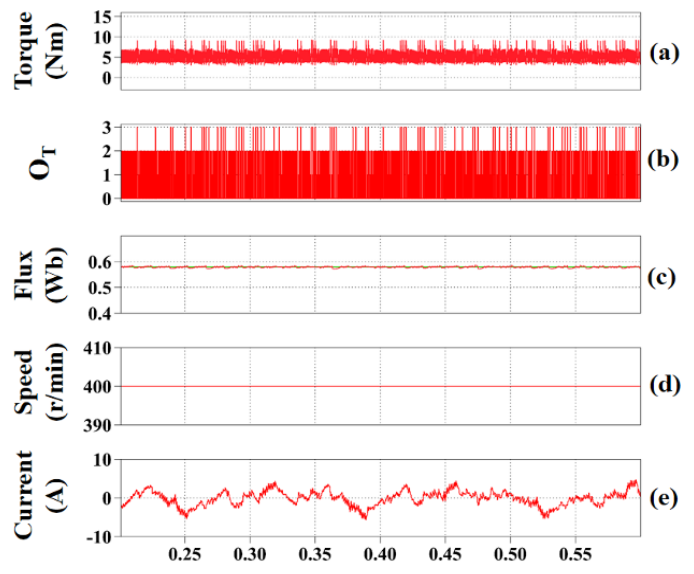

Fig. 9. Normal DTC simulation results without torque ripple reduction method

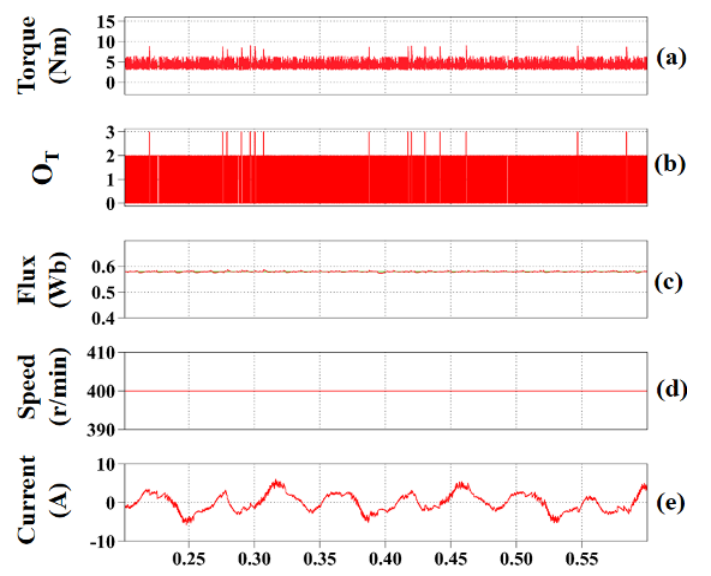

Fig. 10. DTC with torque ripple reduction method simulation results by using the fixed constant value $\left(K_{T}\right)$

reference of rated flux is $0.58 \mathrm{~Wb}$. The $K_{F}$ is set as 0.58 . The results of normal DTC are shown in Fig. 9. The torque and flux comparators are used for the normal DTC. When the torque is produced above the torque reference, it become reduced by the zero voltage vector. On the other hand, if the produced torque is below the torque reference, the torque is increased by non-zero voltage vector. The overall torque value is controlled above the reference of torque by DTC, because if the torque is produced below the torque reference, the torque increases sharply by nonzero voltage vector. The output of the torque comparator is shown in Fig. 9(b). The torque comparator's output is controlled by the torque error. The torque has $5.9 \mathrm{Nm}$ value by the large voltage vector. Also, the torque is increased about $3.3 \mathrm{Nm}, 1.6 \mathrm{Nm}$ by the medium voltage vector and small voltage vector. As a result, the maximum torque is $9.3 \mathrm{Nm}$, the minimum output of the torque is $3.1 \mathrm{Nm}$ and the torque average is $5.35 \mathrm{Nm}$. The flux which is controlled by rated flux value $(0.58 \mathrm{~Wb})$ is shown in Fig. $9(\mathrm{c})$.

In addition, by using the fixed speed motor as load in this simulation, the speed is fixed at $400 \mathrm{rpm}$ as indicated 
in Fig. 9(d). The current of phase-A is shown in Fig. 9(e). The DTC with the torque ripple reduction method by using the fixed constant value $\left(K_{T}\right)$ is shown in Fig. 10. Fig. 10(a) shows the output torque. The maximum output torque value is $8.8 \mathrm{Nm}$, the minimum output of torque value is 3.0 $\mathrm{Nm}$ and the average torque value is $4.46 \mathrm{Nm}$.

The simulation result of Fig. 10(a) by using the fixed constant value $\left(K_{T}\right)$ is reducing the torque ripple compare to Fig. 9(a), and the flux is controlled by rated flux 0.58 $\mathrm{Wb}$ in $400 \mathrm{rpm}$. The results of the proposed method are shown in Fig. 11. The fuzzy system input has the torque error. Thus,

The $K_{T}$ value is the optimal value in each control period. Fig. 11(a) indicates the output torque of proposed torque ripple reduction method. The maximum torque is $7.15 \mathrm{Nm}$, the minimum torque is $3.0 \mathrm{Nm}$. As a result, the average torque becomes $3.97 \mathrm{Nm}$.

Table 4 is listed in the simulation results of the torque ripple analysis. The proposed torque ripple reduction me thod uses fuzzy controller for calculating the voltage vector injection time. It is possible to reduce the torque ripple more than at least $30 \%$, compared with the conventional DTC algorithm. The proposed method possesses lowest torque ripple in Table 4.

Fig. 12 shows simulation results of the transient state by using the proposed torque ripple reduction method. A step torque command is applied to the five-phase induction motor. Torque reference is changed from $2 \mathrm{Nm}$ to $7 \mathrm{Nm}$ in $300 \mathrm{rpm}$ and $600 \mathrm{rpm}$. The torque is controlled by the reference torque acquired using the proposed method in transient state. It can be seen from the simulation results

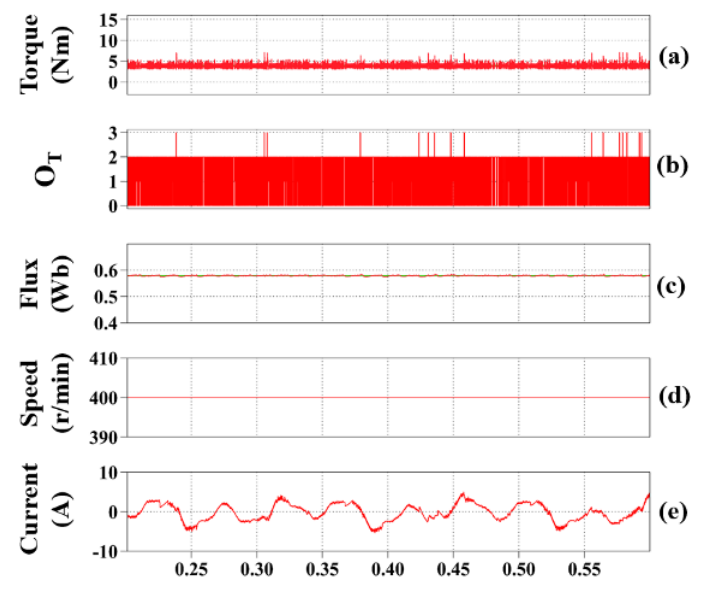

Fig. 11. DTC with torque ripple reduction method simulation results by the proposed method

Table 4. Comparison of the simulation result

\begin{tabular}{c|c|c|c|c}
\hline Torque & $\begin{array}{c}\text { Max. } \\
(\mathrm{Nm})\end{array}$ & $\begin{array}{c}\text { Min. } \\
(\mathrm{Nm})\end{array}$ & $\begin{array}{c}\text { Avg. } \\
(\mathrm{Nm})\end{array}$ & $\begin{array}{c}\text { Avg. } \\
\text { Reduction ratio } \\
(\%)\end{array}$ \\
\hline Basic DTC & 9.3 & 3.0 & 5.35 & - \\
\hline The fixed $K_{T}$ & 8.8 & 3.0 & 4.46 & 65.9 \\
\hline The proposed method & 7.15 & 3.0 & 3.97 & 97.7 \\
\hline
\end{tabular}

above that the proposed method has good performance in terms of torque control characteristic, particularly, in the low speed region. On the other hand, torque ripple increases in the high speed region in Fig. 12 as a rising slope of the torque is increased by motor speed.

Fig. 13 shows the simulation results of the DTC in high torque and speed state. Fig. 13(a) is the result of the conventional torque ripple reduction method. The Torque is not controlled by the reference torque. Average torque of the Fig. 13(a) is $5.8 \mathrm{Nm}$. The ratio of the effective voltage vector injection time is increased in high torque and speed state. However, the conventional method cannot increase enough the effective voltage vector injection time ratio as this method uses a fixed value for calculating the $T_{S}$. Thus, the conventional method always has a zero voltage vector insertion time ratio. As a result, the torque is controlled under the torque reference. On the other hand, the torque is controlled by the reference torque using the proposed torque ripple reduction method in Fig. 13(b).

Fig. 14 shows torque of the DTC about $5 \mathrm{Nm}$ by changing $K_{F}$. It can be shown from the simulation results above that the torque average has the similar value by changing $K_{F}$. As a result, $K_{F}$ is able to fix as 0.58 which is the rated flux value.

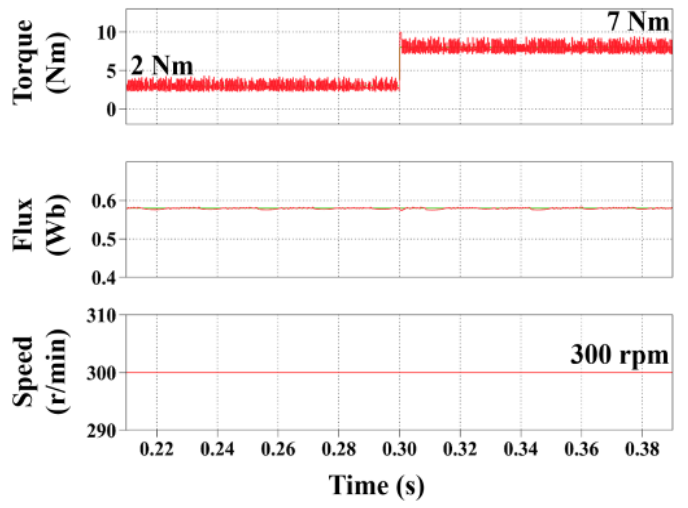

(a)

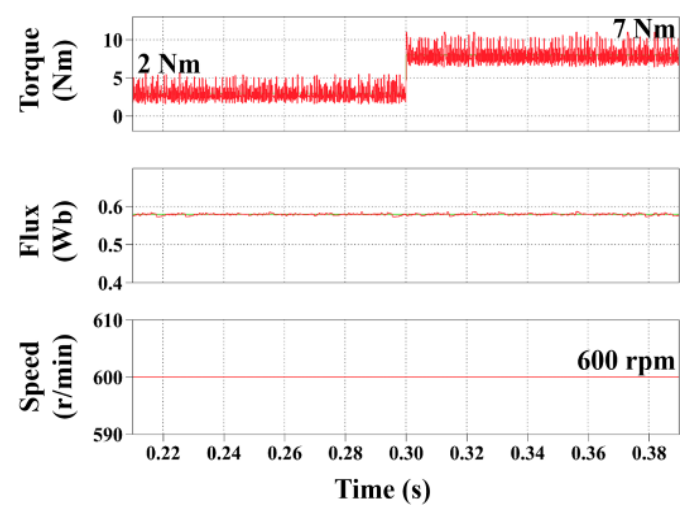

(b)

Fig. 12. Simulation results of the DTC in transient state (2 $\mathrm{Nm} \rightarrow 7 \mathrm{Nm}$ ) by using the proposed method: (a) $300 \mathrm{rpm}$ and (b) $600 \mathrm{rpm}$ 


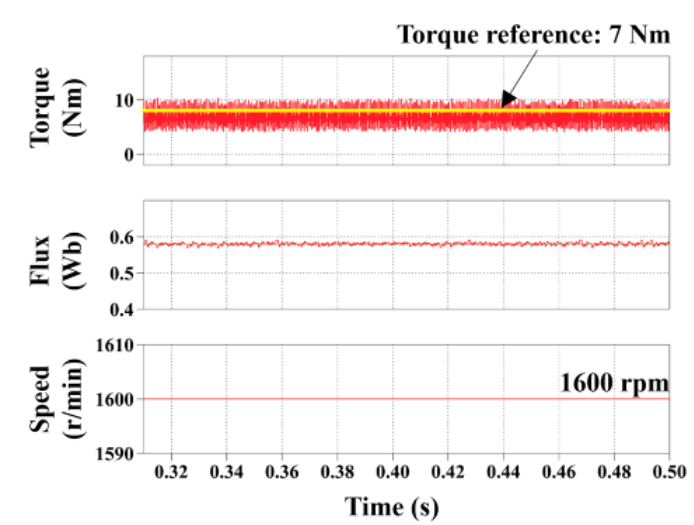

(a)
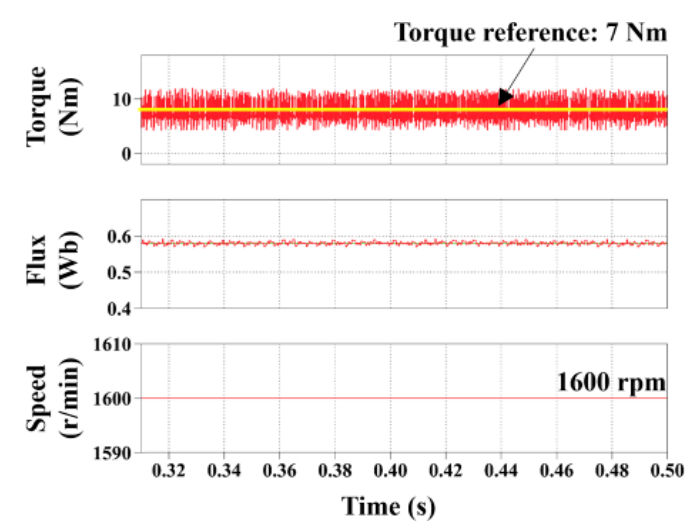

(b)

Fig. 13. Simulation results of the DTC in high torque and speed state: (a) conventional torque ripple reduction method and (b) proposed torque ripple reduction method

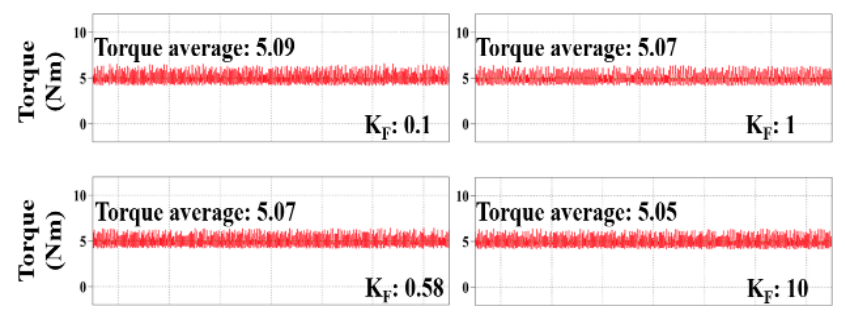

Fig. 14. Simulation results of the DTC $(5 \mathrm{Nm})$ by changing $K_{F}$

\section{Experiment Results}

The motor specification is listed in Table 5. The experimental set consists of the load motor, the five-phase induction motor, the control board, and the power board as shown in Fig. 15. DSP controller TMS320F 28335 from Texas Instruments is used for the digital implementation of the proposed techniques. The sampling time of the digital controller in the experimental setup is set to $150 \mu$ s. The electromagnetic torque is estimated by the deterministic model [24].
Table 5 Specification of five-phase induction motor

\begin{tabular}{c|c}
\hline \multicolumn{2}{|c}{ Motor specification } \\
\hline Capacity & $1.5 \mathrm{~kW}$ \\
\hline Rated voltage & $220 \mathrm{~V}$ \\
\hline Rated frequency & $60 \mathrm{~Hz}$ \\
\hline Rated current & $4.9 \mathrm{~A}$ \\
\hline Rated speed & $1684 \mathrm{rpm}$ \\
\hline
\end{tabular}

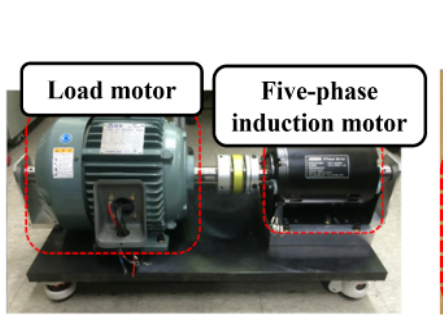

(a)

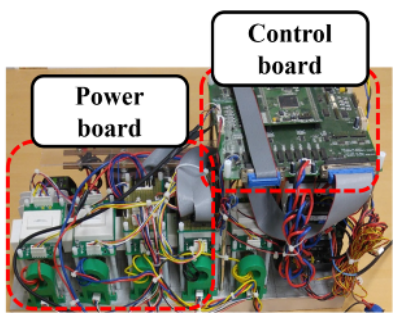

(b)
Fig. 15. Experimental set-up: (a) Five-phase induction motor and load motor and (b) control board and power board

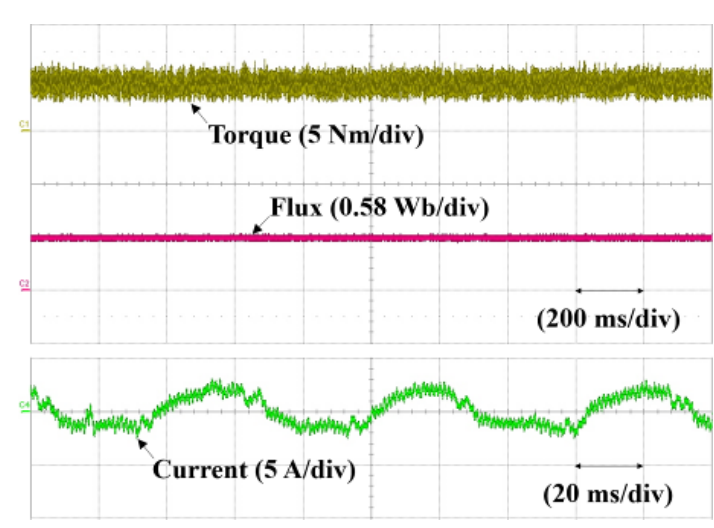

Fig. 16. Experiment result of the DTC with torque ripple reduction method by using the fixed constant value $\left(K_{T}\right)$

Fig. 16 and 18 show the experiment results in accordance with the simulations. The experiment result of the torque ripple reduction method for the DTC by using the fixed constant value $\left(K_{T}\right)$ is shown in Fig. 16. This figure shows the output torque, output flux, and output current of phase-A. The reference output torque is $4 \mathrm{Nm}$ and flux is controlled by the rated flux of $0.58 \mathrm{~Wb}$ in this experiment. This figure indicates the output torque, the output flux, and the output current of phase-A. In experimental results, the maximum torque ripple is $3.7 \mathrm{Nm}$ due to the maximum torque of $6.6 \mathrm{Nm}$ and the minimum torque of $2.9 \mathrm{Nm}$. This torque ripple reduction method reduces the torque ripple compared to the normal DTC. The current ripple of phase-A is also reduced together with the torque ripple reduction.

The experimental result of the proposed torque ripple reduction method is shown in Fig. 17. Fig. 17 indicates the output torque, output flux, and output current of phase-A. 


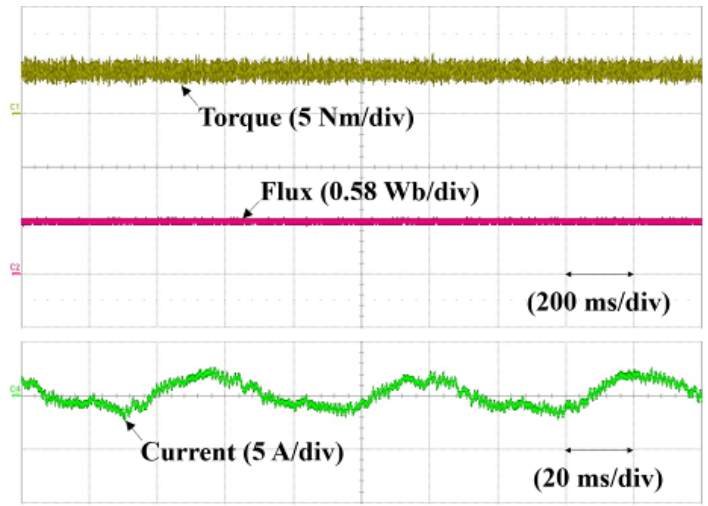

Fig. 17. Experiment result of the DTC with torque ripple reduction method by the proposed method

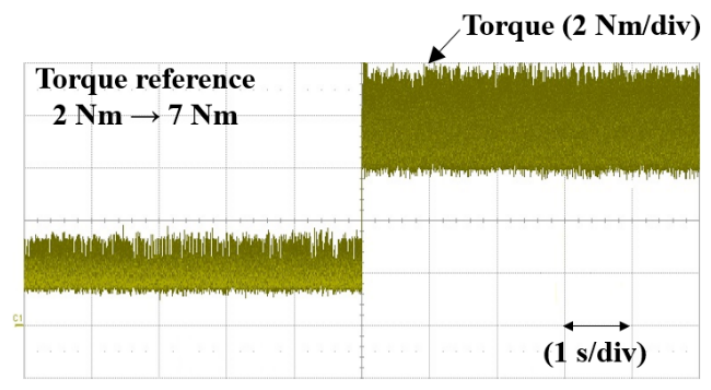

(a)

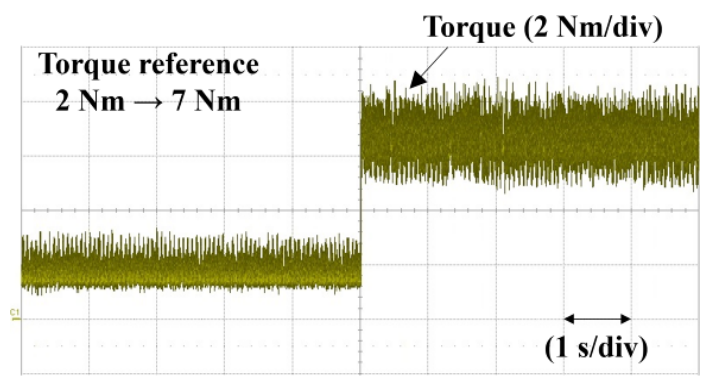

(b)

Fig. 18. Experiment results of the DTC in a transient state $(2 \mathrm{Nm} \rightarrow 7 \mathrm{Nm})$ (a) conventional method and (b) proposed method

In this experimental result, the maximum torque ripple is $1.4 \mathrm{Nm}$ with the maximum output torque of $5.1 \mathrm{Nm}$ and the minimum output torque of $3.7 \mathrm{Nm}$. As a result, the output torque ripple and the current ripple of phase-A are reduced when the proposed torque ripple reduction method is compared with the result of torque ripple reduction method by using the fixed constant value and normal DTC method. A quasi-rectangular input current induces the nearly rectangular flux linkage in the air-gap and thus results in higher power density and more torque output.

Fig. 18 shows the experiment results in a transient state. The torque reference is changed from $2 \mathrm{Nm}$ to $7 \mathrm{Nm}$. The torque is controlled by its reference using both the conventional method and proposed method in a transient state. However, torque ripple of Fig. 18(b) is decreased by

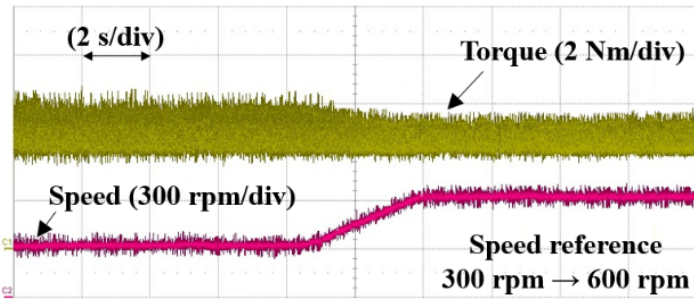

(a)

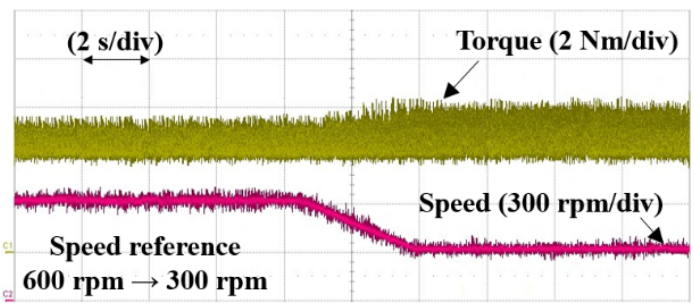

(b)

Fig. 19. Experiment results of the DTC in a speed transient state by using the proposed method (Torque reference is $5 \mathrm{Nm}$ ): (a) $300 \mathrm{rpm} \rightarrow 600 \mathrm{rpm}$ and (b) $600 \mathrm{rpm} \rightarrow 300 \mathrm{rpm}$

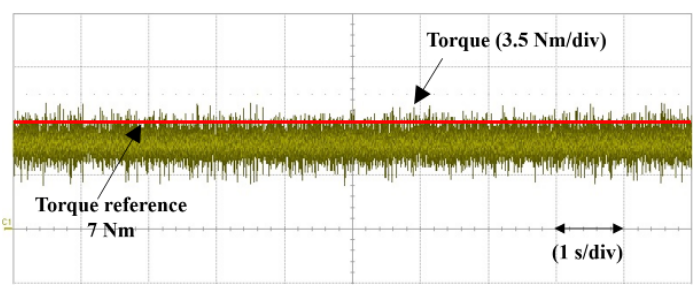

(a)

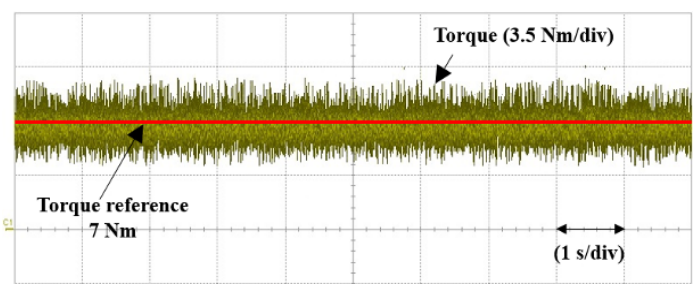

(b)

Fig. 20. Experiment results of the DTC in high torque and speed state $(7 \mathrm{Nm}, 1600 \mathrm{rpm})$ : (a) conventional torque ripple reduction method and (b) proposed torque ripple reduction method

comparing to the conventional method.

Fig. 19 shows the experiment results in a speed transient state by using the proposed method. The torque reference is $5 \mathrm{Nm}$. Speed reference of Fig. 19 (a) is changed from $300 \mathrm{rpm}$ to $600 \mathrm{rpm}$. After that, speed reference of Fig. 19 (b) is changed from $600 \mathrm{rpm}$ to $300 \mathrm{rpm}$. Two results of Fig. 19 are controlled well according to the torque reference. The experiment results of the DTC in high torque and speed state are shown in Fig. 20. Fig. 20(a) shows the conventional torque ripple reduction method. As explained in Fig. 14, the conventional method for the 
torque ripple reduction is not controlled by the torque reference. On the other hand, the proposed control method for the torque ripple reduction has good performance in high torque and speed region.

\section{Conclusion}

An improved torque ripple reduction method in the fivephase induction motor drive for DTC with the optimal selection of the voltage vector has been presented. A proposed method based on the optimal selection of the voltage vector states is conducted in the control period of $150 \mu$ s. Compared to the conventional method of the torque ripple reduction, the proposed method is capable of reducing the torque ripple more than at least $30 \%$. The insertion time of voltage vector is calculated by the fuzzy system in the proposed algorithm which is designed optimally with using the simulation results and testing in this system. Therefore, the proposed method has advantage in the independent motor parameters. Additionally, the optimal voltage vector is used in the proposed algorithm for the torque ripple reduction acquired by considering the torque error in five-phase induction motor. The result of the proposed control schematics providing high performance is shown in experiment and the simulation results.

\section{Acknowledgements}

This research was supported by Basic Science Research Program through the National Research Foundation of Korea (NRF) funded by the Ministry of Science, ICT \& Future Planning (2016R1A2B4010636).

\section{References}

[1] J. A. Riveros, J. Prieto, F. Barrero, S. Toral, M. Jones, and E. Levi, "Predictive Torque Control for FivePhase Induction Motor Drives," in Proc. 36th Annu. Conf. IEEE Ind. Electron. Soc., pp. 2467-2472, 2010.

[2] H. A. Toliyat and H. Xu, "A Novel Direct Torque Control (DTC) Method for Five-Phase Induction Machines," in Proc. IEEE APEC, New Orleans, LA, pp. 162-168, 2000.

[3] K. B. Lee and F. Blaabjerg, "Performance Improvement of DTC for Induction Motor-Fed by Three-Level Inverter with an Uncertainty Observer Using RBFN," IEEE Trans. Energy Convers., vol. 20, no. 2, pp. 276283, Jun. 2005.

[4] M. O. Kizilkaya and K. G, "Feed-Forward Approach in Stator-Flux-Oriented Direct Torque Control of Induction Motor with Space Vector Pulse-Width Modulation," J. Power Electron., vol. 16, no. 3, pp. 994-1003, May. 2016.
[5] Y. N. Tatte and M. V. Aware, "Selection of Voltage Vectors in Three-Level Five-Phase Direct Torque Control for Performance Improvement," J. Power Electron., vol. 16, no. 6, pp. 2162-2172, Nov. 2016.

[6] L. Zheng, J. E. Fletcher, B. W. Williams, and X. He, "A Novel Direct Torque Control Scheme for a Sensorless Five-Phase Induction Motor Drive," IEEE Trans. Ind. Electron., vol. 58, no. 2, pp. 503-513, Feb. 2011.

[7] B. Singh, S. Jain, and S. Dwivedi, "Torque Ripple Reduction Technique with Improved Flux Response for a Direct Torque Control Induction Motor Drive", IET Power Electron., vol. 6, no. 2, pp. 326-342, Feb. 2013.

[8] Y. Zhang and J. Zhu, "A Novel Duty Cycle Control Strategy to Reduce Both Torque and Flux Ripples for DTC of Permanent Magnet Synchronous Motor Drives with Switching Frequency Reduction," IEEE Trans. Power Electron., vol. 26, no. 10, pp. 30553067, Oct. 2011.

[9] X. Xiao and C. Chen, "Reduction of Torque Ripple Due to Demagnetization in PMSM Using Current Compensation," IEEE Trans. Appl. Supercon., vol. 20, issue 3, pp. 1068-1071, Jun. 2010.

[10] Y. S. Cho, K. B. Lee, Y. I. Lee, and J. H. Song, "Torque-Ripple Minimization and Fast Dynamic Scheme for Torque Predictive Control of PermanentMagnet Synchronous Motors," IEEE Trans. Power Electron., vol. 30, no. 4, pp. 2182-2190, Apr. 2015.

[11] Y. Zhang, J. Zhu, W. Xu, and Y. Guo, "A Simple Method to Reduce Torque Ripple in Direct TorqueControlled Permanent-Magnet Synchronous Motor by Using Vectors with Variable Amplitude and Angle," IEEE Trans. Ind. Electron., vol. 58, no. 7, pp. 28482859, Jul. 2011.

[12] Y. Zhang and J. Zhu, "Direct Torque Control of Permanent Magnet Synchronous Motor with Reduced Torque Ripple and Commutation Frequency," IEEE Trans. Power Electron., vol. 26, no. 1, pp. 235-248, Jan. 2011.

[13] T. Ramesh, A. K. Panda, and S. S. Kumar, "MRAS Speed Estimator Based on Type-1 and Type-2 Fuzzy Logic Controller for the Speed Sensorless DTFCSVPWM of an Induction Motor Drive," J. Power Electron., vol. 15, no. 3, pp. 730-740, May. 2015.

[14] S. Y. Kang, H. U. Shin, and K. B. Lee, "Improved Torque Ripple Reduction Method of Five-Phase Induction Motor Using Fuzzy Controller," in Proc. IPEMC-ECCE Asia Conf., pp. 635-640, 2016.

[15] Y. N. Tatte and M. V. Aware, "Torque Ripple Reduction in Five-Phase Direct Torque Controlled Induction Motor," in Proc. PEDES Conf., pp. 1-5, 2014.

[16] L. R. L. V. Raj, A. Jidin, Z. Ibrahim, K. A. Karim, M. A. Said, and M. H. Jopri, "Optimal Torque Control Performance of DTC of 5-Phase Induction Machine," 
in Proc. ICEMS Conf., pp. 2094-2099, 2013.

[17] G. Foo and M. F. Rahman, "Sensorless Direct Torque and Flux-Controlled IPM Synchronous Motor Drive at Very Low Speed without Signal Injection," IEEE Trans. Ind. Electron., vol. 57, no. 1, pp. 395-403, Jan. 2010.

[18] K. B. Lee, J. H. Song, I. Choy, and J. Y. Yoo, "Torque Ripple Reduction in DTC of Induction Motor Driven by Three-Level Inverter with Low Switching Frequency," IEEE Trans. Power Electron., vol. 17, no. 2, pp. 255-264, Mar. 2002.

[19] K. K. Shyu, J. K. Lin, V. T. Pham, M. J. Yang, and T. W. Wang, "Global Minimum Torque Ripple Design for Direct Torque Control of Induction Motor Drives," IEEE Trans. Ind. Electron., vol. 57, no. 9, pp. 31483156, Sep. 2010.

[20] R. Arulmozhiyal, "Design and Implementation of Fuzzy PID Controller for BLDC Motor Using FPGA," in Proc. PEDES Conf., pp. 1-6., Dec. 2012.

[21] R. J. Wai and K. H. Su, "Adaptive Enhanced Fuzzy Sliding-Mode Control for Electrical Servo Drive," IEEE Trans. Ind. Electron., vol. 53, no. 2, pp. 569580, Apr. 2006.

[22] H. H. Choi, H. M. Yun, and Y. Kim, "Implementation of Evolutionary Fuzzy PID Speed Controller for PM Synchronous Motor," IEEE Trans. Ind. Informat., vol. 11, no. 2, pp. 540-547, Apr. 2015.

[23] C. L. Tseng, S. Y. Wang, S. C. Chien, and C. Y. Chang, "Development of a Self-Tuning TSK-Fuzzy Speed Control Strategy for Switched Reluctance Motor," IEEE Trans. Power Electron., vol. 27, no. 4, pp. 2141-2152, Apr. 2012.

[24] L. Zheng, J. E. Fletcher, B. W. Williams, and X. He, "A Novel Direct Torque Control Scheme for a Sensorless Five-Phase Induction Motor Drive," IEEE Trans. Ind. Electron., vol. 58, no. 2, pp. 503-513, Feb. 2011.

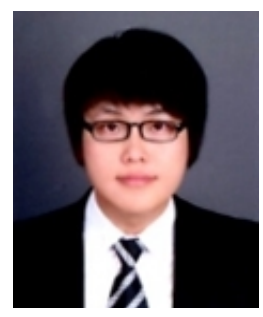

Hye-Ung Shin He received the B.S. in Electrical and Computer Engineering from Kunsan University, Kunsan, Korea, in 2012. He received the M.S. in Department of Electronic Systems Engineering from Hanyang University, Ansan, Korea, in 2014. He received the Ph.D. degree in electrical engineering from the Ajou University, Suwon, Korea, in 2017. His research interests include machine design, electric machine drives and power conversion.

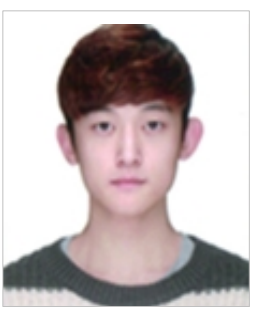

Seong Yun Kang He received the B.S. and M.S. degrees in electrical and electronic engineering from the Ajou University, Suwon, Korea, in 2015 and 2017, respectively. Since 2017, he has been with the Dawonsys Co., Ltd, from Ansan, Korea in present. His research interests include motor drives and grid-

connected systems.

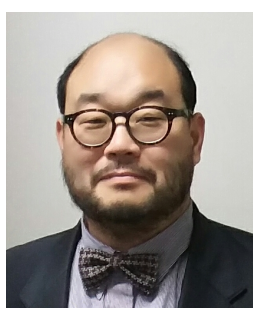

Kyo-Beum Lee He received the B.S. and M.S. degrees in electrical and electronic engineering from the Ajou University, Suwon, Korea, in 1997 and 1999, respectively. He received the $\mathrm{Ph} . \mathrm{D}$. degree in electrical engineering from Korea University, Seoul, Korea, in 2003. From 2003 to 2006, he was with the Institute of Energy Technology, Aalborg University, Aalborg, Denmark. From 2006 to 2007, he was with the Division of Electronics and Information Engineering, Chonbuk National University, Jeonju, Korea. In 2007, he joined the Department of Electrical and Computer Engineering, Ajou University, Suwon, Korea. His research interests include electric machine drives, renewable power generations, and electric vehicle applications. 